\title{
Antecedentes para el análisis de la monarquía como sistema de gobierno para el pueblo judío
}

Background for the analysis of the monachy as a government system for the Jewish people

\author{
Aliza Moreno-Goldschmidt \\ Museo Interactivo Judío \\ info@mij.cl
}

\section{Resumen}

La vigencia del análisis del régimen monárquico en la historia del pueblo judío radica en que si bien el Estado de Israel no basa su legislación en la ley religiosa, su lazo con la tradición judía es significativo. Por ello, la pregunta sobre el sistema de gobierno ideal de acuerdo a las fuentes y los distintos actores que allí debaten, requiere un profundo estudio. Desde el origen del deseo por tener un rey hasta los fundamentos éticos, políticos y de liderazgo que se observan en especial en el Rey David, de cuya dinastía -dice la tradición judía clásica- provendrá la redención del mundo.

Palabras claves: Rey David - Monarquía - Judío - Samuel - Jueces.

\begin{abstract}
The validity of the analysis of the monarchic regimen in the Jewish people history lies in the fact that although the State of Israel doesn't base its law in the religious lay, its bond with Jewish tradition is meaningful. That is why the question about the ideal government system regarding our sources and the different actor that debate there, needs a profound study. From the origin of the willing for a King to the ethical, political and leadership shown especially in King David, whose dynasty -according with Jewish tradition- will bring world's redemption.
\end{abstract}

Key words: King David - Monarchy - Jew, Samuel - Judges. 


\section{a. Introducción}

De acuerdo al relato bíblico ${ }^{1}$, la historia de los Hijos de Israel comienza en la Época de los Patriarcas. Tal y como se relata en el libro del Génesis, el origen del Pueblo de Israel se remonta a Abraham, el Hebreo.

Abraham, hijo de Téraj, nació en Ur (Mesopotamia) y migró a la Tierra de Canaán (hoy Israel) donde se asentó. Según la Torá, Dios se reveló a los Patriarcas, Abraham, Isaac (su hijo) y Jacob (su nieto), los ayudó y guió a lo largo de sus vidas. De acuerdo con el relato, Dios prometió a los Patriarcas que su descendencia se multiplicaría, se convertiría en un gran pueblo y serían herederos de la Tierra de Canaán.

Aunque los patriarcas residieron en la tierra de Canaán, el pueblo se comenzó a forjar en Egipto, donde los hijos de Jacob (nieto de Abraham y quien sería conocido posteriormente como Israel) descendieron debido al hambre que reinaba en la Tierra de Canaán. En Egipto se les dio un lugar para vivir y pastorear, y pronto se multiplicaron.

Gracias a José (Iosef), uno de los hijos de Jacob que se desempeñaba como viceministro del Faraón, los Hijos de Israel prosperaron en gran medida. Según la tradición bíblica, las generaciones siguientes dejaron de ser una familia para convertirse en un pueblo que, tiempo después, fue esclavizado.

\footnotetext{
${ }^{11}$ Tomando en consideración que el tema central del presente artículo aborda aspectos del pensamiento judío según la literatura rabínica post-bíblica, hemos considerado irrelevante presentar en esta ocasión los importantes debates de la crítica bíblica respecto a la datación y origen de los textos bíblicos. En este sentido cabe señalar que cuando nos referimos a los contenidos bíblicos estos son presentados en su forma simple y literal, tal y como figuran en el texto.
} 
La esclavitud en Egipto se prolongó cientos de años hasta que Moisés, hijo de una familia de hebreos, que fue criado por la hija del Faraón, fue llamado por Dios para liderar al Pueblo de Israel y redimirlo de la esclavitud.

Tal y como se relata en los libros del Éxodo, Levítico, Números y Deuteronomio, la travesía del Pueblo de Israel por el desierto se prolongó cuarenta años. En el inicio de esta travesía, al pie del Monte Sinaí, el pueblo recibió las Tablas de la Ley.

En ellas fue escrita parte de la Torá, sistema de leyes integral destinado a diseñar un estilo de vida para un pueblo soberano en su tierra. A lo largo de su recorrido por el desierto el pueblo se distribuyó en tribus y se organizó militarmente. En vísperas de la entrada a la Tierra de Canaán, Moisés murió y el liderazgo quedó a cargo de su principal discípulo, Josué (Yehoshua) Ben Nun.

El asentamiento de las Tribus está descrito en las fuentes. En el Libro de Josué y en el de Jueces se relata el establecimiento de las doce Tribus en la Tierra de Canaán, luego de su salida de Egipto.

En la continuidad cronológica tuvo lugar lo que se conoce como la Época de los Jueces. Se trató de un período diferente al anterior, tanto a nivel del comportamiento del pueblo, como del de sus líderes. Durante el liderazgo de Moisés y de Josué, existió una conducción fuerte que contaba con el reconocimiento de todo el pueblo. Al contrario, en la época de los Jueces, la vida de los hijos de Israel se desarrolló según su división en tribus.

Hay aquí una paradoja. Por un lado la distribución de los asentamientos en tribus aseguró el éxito en la conquista del territorio mientras que, al mismo tiempo, debilitó la cooperación mutua para la defensa ante los enemigos externos. Se crearon intereses regionales en cada 
una de las tribus, surgieron conflictos a nivel económico (parcelación del terreno y explotación), a nivel político (predominio de una tribu por sobre las otras). Los miembros de Israel debían ser fieles al pueblo en general, y a su tribu en particular. Cada una de las tribus tenía su propia administración social conformada por la Asamblea de Ancianos. Este sistema, particular de cada tribu, se estableció como el más estable. Esporádicamente, cuando surgía algún problema o conflicto militar, se establecía un Juez General. Este Juez era aceptado por una o varias tribus y su decisión afectaba exclusivamente al problema específico para el que había sido convocado. Se trataba de un régimen inherentemente temporal. El Juez mismo padeció esta transitoriedad, en tanto los criterios para su elección también se modificaban esporádicamente.

La época de los Jueces preparó al pueblo para el próximo período, la época de los Reyes. El Profeta Samuel fue el punto de inflexión entre los dos períodos.

La nueva era fue el reflejo del deseo de unidad, de una identidad clara y de un régimen sólido. El interés por el cambio estuvo dado no tanto por una visión ética y moral de futuro, como por una necesidad de cambio de rumbo ante un ambiente duro y difícil.

\section{b. El Régimen Monárquico}

Samuel fue un gran profeta, aceptado a modo general por el pueblo, pero en contraste, sus hijos no se encontraban a la altura para asumir el liderazgo del pueblo. Por ello, cuando Samuel envejeció, la Asamblea de Ancianos le solicitó que nombrara un Rey. A pesar de la oposición de Samuel al establecimiento de un reinado, la Biblia relata que Dios le indica acceder al pedido del pueblo y ungir al rey.

Es importante señalar que, a pesar del desacuerdo de Samuel, la coronación de un Rey para los Hijos de Israel en el momento de su asentamiento en la Tierra de Israel, es señalada ya 
en el Deuteronomio, aun cuando, de acuerdo con la visión tradicional, este libro fue escrito durante la estadía del Pueblo en el desierto, previa su entrada en la Tierra de Canaán.

David fue el segundo rey en la historia del pueblo judío. Su reinado fue posterior al del Rey Saúl y, a pesar de no haber sido el primer monarca, el Rey David se transformó en el ícono de la época de los reyes para todas las generaciones del pueblo de Israel. Su nombre se engrandeció a tal punto que la tradición judía determinó que el Mesías provendría de la dinastía de David (Jeremías 33:15; Ezequiel 37:25).

Si bien es cierto que es imposible poner en duda la importancia histórica que tuvo la figura de David para la cultura de Israel, no ocurre lo mismo cuando nos referimos a su reinado.

Según la historia judía reflejada en el texto bíblico, el régimen monárquico aparece en una época relativamente tardía. La monarquía se hace presente cuando el Pueblo de Israel ya había logrado construir una memoria colectiva, después de la salida de Egipto y del recibimiento de la Torá, y luego de la conquista de la Tierra de Israel y del asentamiento de las doce tribus. Por ello no es posible relacionar el ascenso del régimen monárquico con el proceso de conformación nacional.

Ya en Génesis hay referencias al tema de la monarquía, cuando Dios bendice a Jacob y cambia su nombre por Israel: "Dios se apareció a Jacob una vez más a su llegada de Paddán Aram y le bendijo. Le dijo Dios: "Tu nombre es Jacob, pero ya no te llamarás, sino que tu nombre será Israel. Y le llamó Israel. Le dijo Dios: Yo soy el Señor tu Dios. Sé fecundo y multiplícate. Un pueblo, una asamblea de pueblos tomará origen de ti y saldrán reyes de tus entrañas. La tierra que di a Abraham e Isaac, a ti te la doy, y a tu descendencia y sucesión daré esta tierra". (Génesis 35:9-12). En este texto, entre otras cosas, Dios le promete a Jacob que de su simiente nacerán reyes. Más allá de esta promesa, no hay evidencias suficientes para determinar que la Torá presenta a la monarquía como la forma de gobierno 
ideal. Las dos fuentes centrales en las que se debate el nombramiento de reyes son Deuteronomio y el Libro de Samuel. En estos dos casos los textos son complicados y es posible interpretarlos de múltiples maneras.

En Deuteronomio está escrito: "Cuando entres en el país que el Señor, tu Dios, te dará, cuando lo tomes en posesión y vivas en él, si alguna vez dices: Voy a poner un rey para que me gobierne, como todas las naciones que están a mi alrededor, pondrás un rey elegido por el Señor, tu Dios, que pertenezca a tu mismo pueblo. No podrás someterte a la autoridad de un extranjero, de alguien que no pertenezca a tu pueblo". (Deuteronomio 17:14-15). Por una parte el relato dice "pondrás un rey", de aquí es posible interpretar, tal como lo hizo Maimónides, que el nombramiento de un monarca durante el asentamiento en la Tierra de Israel es un precepto positivo. Por otra parte, este precepto, a diferencia de otros mandatos de la Torá que son independientes, aparece en un contexto determinado y particular: "voy a poner un rey para que me gobierne, como todas las naciones que están a mi alrededor". Sobre el significado de este mandato y su contexto, se despiertan varias interrogantes: ¿Si el establecimiento de un Rey fue parte del planteamiento original, puede entenderse de esto que esta forma de gobierno es el régimen ideal para el pueblo que vive en su tierra? O por el contrario, ¿será el régimen monárquico el resultado del deseo del pueblo de parecerse a las demás naciones?

En el "Libro de Samuel", el mismo libro que describe con lujo de detalles el establecimiento monárquico, el reinado de Saúl y el reinado de David, presenta de forma incluso más crítica el nombramiento del Rey: "Entonces se reunieron todos los Ancianos de Israel y acudieron a Samuel en Ramá. Tú ya eres viejo, le dijeron, y tus hijos no siguen tus pasos. Ahora danos un rey para que nos gobierne, como lo tienen todas las naciones. A Samuel le disgustó que le dijeran: Dános un rey para que nos gobierne, y oró al Señor. El Señor dijo a Samuel: Escucha al pueblo en todo lo que ellos digan, porque no es a ti a quien rechazan: me rechazan a mí, para que no reine más sobre ellos (...) Por eso, escucha su reclamo. Pero les harás una solemne advertencia y les explicarás cuál es el derecho del rey que reinará sobre ellos". (Libro de Samuel I, 8:4-9). El texto presenta de forma detallada 
que el Profeta Samuel no recibió con buenos ojos el pedido de la Asamblea de Ancianos de designar un Rey. Y no sólo ello, a pesar de su acuerdo, también las palabras de Dios se refieren de manera negativa a dicho pedido: "porque no es a ti a quien rechazan". Pero más allá de todo, Dios ordena el nombramiento de un rey, definiendo y restringiendo sus facultades. Este "Derecho del Rey" fue presentado por Samuel ante la Asamblea de Ancianos previa elección del Rey Saúl.

Ya en la época de los Sabios de la Ley Oral se dieron debates en torno al significado de la designación de un rey. Dos enfoques surgen como resultado de aquellas discusiones entre Rabí Yehudá y Rav, en relación al sentido que asumen las palabras del Profeta Samuel que se citan a continuación: "Dijo Rabí Yehudá, dijo Samuel (aquí se refiere al sabio Samuel, no al profeta): todo lo dicho aquí le está permitido al rey. Rav dijo: lo que fue dicho no fue dicho sino para amenazarlos, es decir no pongas para ti un rey que no es necesario" (Talmud Babel, Sanedrín 20,2). Es decir que, por un lado, de acuerdo a Rabí Yehudá (en nombre de Samuel), lo dicho en el relato sobre el pedido de nombramiento de un rey viene a enseñarnos que el establecimiento de una monarquía está permitido. Es decir, no es algo prohibido pero tampoco es un imperativo. Por otra parte, según Rav, la intención del discurso del Profeta Samuel fue infundir temor entre los Ancianos de la Asamblea ante el régimen monárquico. Es decir que, de acuerdo con este enfoque, la monarquía en sí misma es una cosa no deseable, negativa y por supuesto no recomendada desde la perspectiva judía.

Además de estas dos posiciones es posible encontrar en el Talmud otra línea de pensamiento más extrema, según la cual el nombramiento de un rey era uno de los imperativos del pueblo a la hora de su entrada en la Tierra de Israel: "Tres preceptos debía cumplir el Pueblo de Israel tras su entrada a la Tierra Prometida, proclamar para sí un rey, destruir la simiente de Amalec y construir el Templo". (Sanedrín 20, 2). 
Parte de los grandes sabios de la Edad Media adoptaron esta idea y se refirieron al nombramiento del rey como uno de los preceptos positivos de la Torá, por ejemplo Rambam (Maimónides), en su libro "Mishné Torá" y Rambán (Najmánides) en su interpretación al Pentateuco y el "Sefer Hajinuj" (Libro de la Educación). Sin embargo hubo también voces que se opusieron a este sistema. En la opinión de Sforno, quien continúa en cierta medida la postura de Rabí Yehudá, la proclamación de un rey es un derecho opcional (y no una obligación). En definitiva, Sforno presenta de manera negativa este sistema de dominación comparándolo con otros actos de lujuria. En otras palabras, se trata de un compromiso de la Torá con el fin de hacer frente a la maldad incontrolable (si no es posible impedir la proclamación de un monarca, al menos se deberá definir y limitar su autoridad).

Justamente Rabí Ytzjak Avarbanel, quien obró a lo largo de su vida en las cortes de varias monarquías (Portugal, España y Nápoles), representa la postura más crítica en contra de este régimen. Avarbanel niega todo aspecto positivo respecto a este sistema de gobierno y considera que la monarquía no solamente que no es el sistema ideal o una orden divina, sino que por el contrario consiste en un sistema de gobierno absolutamente indeseable, que conlleva a la corrupción de gobernantes, a la opresión del pueblo y por lo tanto al alejamientos de los ideales religiosos y sociales del judaísmo.

Esta discusión tiene consecuencias trascendentales en nuestros tiempos, luego de una milenaria diáspora, cuando el Pueblo de Israel volvió a lograr un régimen independiente en su tierra. A pesar de que el Estado de Israel no fue creado como un estado basado en la ley religiosa, su lazo con la tradición judía es profundo y significativo. Por ello la pregunta sobre el sistema de gobierno ideal de acuerdo a las fuentes, es también relevante en la actualidad.

La discusión clásica aquí mencionada entre los pensadores judíos respecto del sistema de gobierno, nos ofrece una perspectiva importante que debe tomarse en consideración: en 
realidad no existe dentro de la tradición del pueblo judío una respuesta única y definitiva a esta pregunta. Si bien es cierto que existe una clara tradición según la cual una de las características de la época mesiánica sería el restablecimiento de la monarquía de la Casa de David, también es verdad que esta no es una tradición que haya sido aceptada al unísono por todos los pensadores y exégetas del pueblo judío a lo largo de las generaciones.

Desde su creación, el Estado de Israel ha sido la democracia por excelencia del Medio Oriente. Los ideales democráticos como sistema de gobierno del estado judío moderno nunca fueron, ni han sido, puestos en tela de juicio, ni por los forjadores ideológicos de la nación, ni por los líderes de las corrientes centrales de la política israelí de todos los tiempos. En este sentido no cabe duda que la calidad democrática de dicho estado no es un tema que genere debate. Más complejo resulta el intento de otorgar un carácter judío a dicho estado. ¿Acaso son compatibles los valores democráticos modernos con los ideales políticos tradicionales, según se reflejan en los textos judíos clásicos? Aparentemente existe una contradicción carente de solución, especialmente si nos aferramos a la tradición según la cual el renacimiento nacional del pueblo judío significa la restitución de la monarquía de la Casa de David.

Para el público y los líderes laicos en Israel este tema en realidad no constituye un problema o un desafío. Entre estos, incluso quienes son partidarios de adjudicar un carácter judío indiscutible al estado moderno -es decir la mayoría de los israelíes laicos-, consideran que la tradición judía es la que otorga el carácter particular al estado. Es decir que los valores judíos son los que permiten la justificación histórica del sionismo y son más bien de carácter cultural sin tratarse de imperativos religiosos dogmáticos. En este sentido, la adopción parcial de la tradición judía por las instituciones israelíes no es observada como una contradicción.

Por otro lado, entre el público religioso existen algunas tendencias que pretenden hacer una distinción entre la existencia del Estado de Israel por un lado y la época mesiánica futura 
por el otro. Es decir que el Estado de Israel es considerado como una realidad histórica temporal, que si bien es positiva, no constituye la concretización del anhelo milenario de la restitución de la visión profética según la cual se levantará pendón a las gentes, y juntará los desterrados de Israel, y reunirá los esparcidos de Judá de los cuatro cantones de la tierra (Isaías 11:12). Por lo tanto, si no se trata de la época mesiánica, no es imperativo que todos los ideales judíos tradicionales se vean manifestados en el Estado de Israel. En este sentido, según esta ideología, no es motivo de conflicto el hecho que dicho estado sea democrático, ya que la restitución de la monarquía y el reinado de la Casa de David tendrán el lugar privilegiado que, según esta visión, otorga la tradición judía, en una época futura.

En el presente artículo hemos ofrecido varios ejemplos a través de los cuales pretendimos demostrar que la tradición judía según se pone de manifiesto en los diversos textos clásicos rabínicos pre-modernos, incluyendo la época de la Ley Oral y medieval, no es concluyente respecto al tipo de gobierno ideal según el judaísmo. A pesar del hecho que en la época antigua los gobiernos de Judá e Israel eran monárquicos, no existe un consenso respecto a la pregunta si este tipo de gobierno constituye un imperativo religioso o no. Esta falta de consenso entre los ideólogos de la cultura judía puede ser considerada como una oportunidad para conciliar entre la certeza del carácter democrático del Estado de Israel y el anhelo de otorgar a dicho estado un carácter judío tradicional.

\section{Bibliografía}

Harvey, W. Z., "Political philosophy and Halakhah in Maimonides", Binah 3 (1994) 47-64.

Hilton, I. "Modern insights into leadership from classical Jewish sources", Australian

Journal of Jewish Studies 21 (2007) 155-169.

Kimelman, R., “Abravanel and the Jewish republican ethos”, Commandment and

Community: New Essays in Jewish Legal and Political Philosophy (1995) 195-216. 
Melamed, A., "The organic theory of the state in medieval and Renaissance Jewish political thought." Wisdom's Little Sister; Studies in Medieval and Renaissance Jewish Political Thought. Boston: Academic Studies Press, 2012, pp. 140-174.

Ravitzky, A., Religion and state in Jewish philosophy: models of unity, division, collision and subordination, Jerusalem: Israel Democracy Institute, 2002.

Ravitzky, A., "Kings and laws in late medieval Jewish thought: Nissim of Gerona vs. Isaac Abrabanel", en: Scholars and Scholarship: the interaction between Judaism and Other Cultures. The Bernard Revel Graduate School Conference Volume.Ed. byLeo Landman. NewYork: Yshiva University Press, (1990) 67-90. 